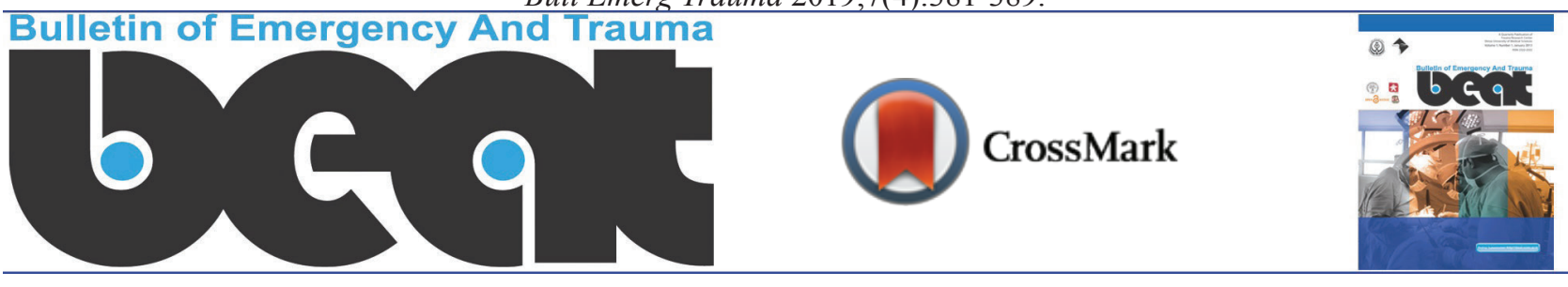

\title{
Identification and Prioritization of Key Components Influencing Prehospital Emergency Related to Preventable Road Traffic Injuries Deaths in Iran; A Delphi Study
}

\author{
Adel Eftekhari ${ }^{1}$, Abbasali Dehghani Tafti ${ }^{1}$, Khadijeh Nasiriani ${ }^{2}$, Majid Hajimaghsoudi ${ }^{3}$, Hossein Fallahzadeh ${ }^{4}$, \\ Davoud Khorasani-Zavareh ${ }^{5 *}$
}

${ }^{1}$ Department of Health in Emergencies and Disasters, School of Public Health, Shahid Sadoughi University of Medical Sciences, Yazd, Iran ${ }^{2}$ Department of Nursing, School of Nursing and Midwifery, Shahid Sadoughi University of Medical Sciences, Yazd, Iran

${ }^{3}$ Trauma Research Center, Shahid Rahnemoon Hospital, Shahid Sadoughi University of Medical Sciences, Yazd, Iran

${ }^{4}$ Department of Biostatistics and Epidemiology, School of Public Health, Shahid Sadoughi University of Medical Sciences, Yazd, Iran

${ }^{5}$ Safety Promotion and Injury Prevention Research Center, Shahid Beheshti University of Medical Sciences, Tehran, Iran

*Corresponding author: Davoud Khorasani-Zavareh

Address: Department of Health in Emergencies and Disasters, School of Public Health and Safety, Shahid Beheshti University of Medical Sciences, Tehran, Iran. Tel: +98-21-22439982; Fax: +98-21-22439784

e-mail: davoud.khorasani@gmail.com
Received: June 13, 2019

Revised: June 29, 2019

Accepted: July 7, 2019

\section{ABSTRACT}

Objective: To identify and prioritize the key Components of prehospital emergency system to prevent mortality in road traffic injuries.

Methods: A total of 25 emergency medicine practitioners, emergency ward nurses, and managers of prehospital emergency centers participated in this adjusted Delphi study in three rounds. After extracting the primary components through reviewing systematic studies and interviewing experts, the Delphi rounds were performed with the presence of experts. The data were analyzed with both qualitative content analysis and quantitative analysis using SPSS20 software. For the analysis and selection of the final priorities, the coefficient of agreement of over $70 \%$ was used.

Results: After doing three Delphi rounds, in the final Delphi round, 10 superior components were selected respectively as follows: correct history taking of the victim, examining possible cervical injury, the time spent from the first call to arrival of technicians to the scene, the time spent from arriving at the scene to the time of hospital transport, passing of re-education courses by EMS technicians, coordination among the rescue organizations, police, the Red Crescent, fire station, and healthcare organizations, integrated commandership at scene, police attendance in the scene before EMS arrival at the scene, proper ambulance equipment with respect to the required equipment $(\mathrm{A}, \mathrm{B}, \mathrm{C})$ on the basis of victim's condition, and coordination with the target hospital for patient transport.

Conclusion: This study determined the most applicable managerial methods of prehospital emergency components pertaining to preventable fatal road traffic injuries through empowerment of EMS systems in the fields of victim assessment, time management indices, personnel training, coordination between the involved organs, and the presence of the main commander in the scene.

Keywords: Preventable mortality; Rroad traffic injuries; Prehospital emergency care; Delphi technique.

Please cite this paper as:

Eftekhari A, Dehghani Tafti A, Nasiriani K, Hajimaghsoudi M, Fallahzadeh H, Khorasani-Zavareh D. Identification and Prioritization of Key Components Influencing Prehospital Emergency Related to Preventable Road Traffic Injuries Deaths in Iran; A Delphi Study. Bull Emerg Trauma. 2019;7(4):381-389. doi: 10.29252/beat-070407. 


\section{Introduction}

A mong the care provision management systems for road traffic crash victims, the prehospital emergency medical services play a significant role [1]. It is a basic and vital component of treatment of emergency patients so that victims first encounter EMS through this system in the civil healthcare system [2]. Prehospital EMS forms an important part of healthcare system playing a key role in prehospital care provision and transport of patients to healthcare centers [3]. Such a system aims at providing medical services and giving proper care at the right time and place using available resources $[4,5]$. Prehospital EMS is defined as services that respond to healthcare needs of individuals out of the hospital setting [6]. The success of this system depends on various factors such as capability of the authorities, trained personnel, sufficient equipment, response time, rescuers' skills level, coordination, and communication [7]. The more rapidly and accurately the victims are cared for in the prehospital phase, the smaller the rate of mortality and disability pertaining to crash and diseases and the greater the people's confidence in the system will be [8-10].The prehospital personnel's performance is of utmost significance due to the different work environment of prehospital rescuers with its unique features. Making the correct decision at critical times betrays its importance more obviously [11]. In this condition, lack of correct and prompt decision-making may prolong and endanger the care process. Clinical care professionals ought to acquire the necessary skills for critical decision-making, collecting and interpreting data, intervention, and assessment [12].

Road traffic injuries (RTIs) cause many deaths and crippling round the globe annually and the prehospital emergency care system plays a significant role in decreasing the related mortality rate [13]. Road traffic injuries are the third leading cause of mortality around the world after cardiovascular diseases and cancer causing 16,000 deaths daily and more than 5,000,000 deaths annually [14]. It is estimated that given the increasing number of RTIs, this rate will reach $8,000,000$ deaths annually by 2020 [15]. The right performance of various parts of the prehospital emergency system would lead to rapid victim transport and ambulance arrival at the scene preventing death and/or disability [16]. If all influential steps are performed comprehensively and promptly, many mortalities and morbidities can be avoided in the prehospital phase. Many countries use preventable death rate in the prehospital phase as an index for measuring quality of healthcare [17]. Some studies have already explored the factors affecting the success of the prehospital emergency care system in the prehospital phase, no study was found to have investigated the role of prehospital emergency services in preventing preventable deaths in global RTIs. It also appears that regarding the variable conditions, geography, and infrastructures of different countries, the issue should be investigated separately and locally for each country [18].

To identify and prioritize the factors affecting preventable death which the pre-hospital emergency role plays, using expert opinions by Delphi method is one of the best practices. The application of this method to decision-making and consensus on issues where objectives and parameters are not explicitly explored lead to very valuable results [19]. In general, the Delphi process is a systematic approach to reaching a group consensus on a specific topic that continually repeats itself to a consensus point of view, and results in more objective results than personal opinions [20]. Consequently, using the Delphi method in this study is the most important advantage. Using expert opinions and consensus approval, a stronger approach has been developed to prioritize effective factors on preventable mortality in the pre-hospital phase of traffic injuries.

\section{Materials and Methods}

This was an adjusted Delphi study in three rounds. Delphi study is a systematic approach in research used to extract opinions of an expert panel on a specific topic or issue to achieve collective consensus through a series of questionnaire rounds using anonymous respondents and feedback of opinions to expert panel [21].

\section{The Delphi Process}

In the first round, the results obtained from two systematic review and qualitative methods were used to extract the factors affecting preventable deaths; The components extracted from the systematic review and qualitative stage are merged with 5 joint sessions with the presence of the research team members and a preliminary questionnaire was prepared. Then, submitted to experts as open-ended questions.

The findings of the systematic review were obtained using the keywords "preventable death, prehospital phase, and road traffic injuries" during May $10^{\text {th }}$, 2018 to August $30^{\text {th }}, 2018$. In this study, the items were distilled after studying 14 papers using content analysis [22].

Moreover, in the qualitative study analyzed with conventional content analysis, 24 experts in the fields of preventable fatality; RTIs including firefighting, road traffic police, the Red Crescent, EMS technicians, emergency medicine specialists, and hospital emergency ward nurses were interviewed and the items were extracted [23].

Subsequently, the extracted factors summarized in the form of a questionnaire with open-ended questions with the possibility of writing answers at the end of each factor were sent by e-mail or manually to 25 experts and technicians. The criteria of the experts include the specialized knowledge, the history of 
injuries caused by traffic accidents, the interest in participating in research, active participation in the study domain. The scope of questions was in the field of subjects such as assessment of scenes and injuries, coordination and communication, time management, training and support. Two weeks were allocated for responding. In the second round, the answers received in the first round were assessed and the corrections intended by experts were made. Then, the components obtained from the first round were sent to the identified experts in the form of a five-point Likert scale (ranging from completely disagree $=1$ to completely agree $=5$ ). In this stage, the items were sent to 10 national experts via e-mail and two weeks were allocated for responding to questionnaires. Additionally, the developed questionnaire was investigated in a focus group session for 90 minutes by experts and researchers at the province level who were involved with casualties, victims and mortalities in EMS and hospitals and consensus was achieved. There were 25 participants in this round. The recommendations on integration, displacement, adding new items, and separation or edition of some factors were applied. The agreed items were identified after calculating the means and SDs. In the third round, the items approved in the second round were sent to experts in the agreed/ disagreed format. They were asked to evaluate the items. The results of this round were used to select and prioritize the 10 superior components in experts' viewpoints. There were 22 experts in this stage and two weeks were allotted for responding. The demographics of the participants in the last Delphi round are presented in Table 1. After analysis of the third round, a meeting was held by the researcher, dissertation supervisors and advisors to discuss the 10 superior components and to select them as the final results.

\section{The Expert Panel}

The validity of Delphi method is not dependent on the number of the participants of the study; rather, it depends on the scientific validity of the experts participating in the study [24]. Generally, there are 15-35 participants [24]. The participants of this study were 25 in the second round and 22 in the third round. The experts were selected on the basis of knowledge and experience of the topic, personal inclination, having sufficient time for participation, and effective communication skills. The experts were selected with purposive sampling method to participate in the Delphi rounds including specialists in health in disasters, emergency medicine, neurosurgery, general surgery, orthopedics, medical emergency technicians, the Red Crescent, fire-fighting organization, official personnel of EMS center, and hospital emergency ward nurses.

\section{Ethical Approval}

This paper is part of a $\mathrm{PhD}$ dissertation in health in disasters approved by Committee of Ethics in Human Research at Shahid Sadoughi University of Medical Sciences, Yazd, central Iran, with code of ethics: IR.SSU.SPH.REC.1397.038 dated 18.6.2018. Oral or written consent was obtained from the experts before sending the items to them. They were assured of information anonymity and confidentiality.

\section{Analysis, Convergence and Consensus}

The method of final analysis in the two and three rounds were median scores of 4 (agree) to 5 (strongly agree) for "agreement", 1 (strongly disagree) to 2 (disagree) for "disagreement", or 3 (unsure) with an interquartile range of 0 to 1 . For the analysis and selection of the final priorities, the coefficient of agreement of over $70 \%$ was used. Statistical package for social sciences (SPSS Inc., Chicago, Illinois,

Table 1. Demographics of experts in the second Delphi round to get final comments

\begin{tabular}{lll}
\hline Demographic variables & Details & Number of participants \\
\hline Gender & Male & 23 \\
\cline { 2 - 2 } Specialty & Female & 2 \\
& Health in disasters & 4 \\
& Emergency medicine & 6 \\
& Neurosurgery & 1 \\
& General surgery & 1 \\
& Orthopedics & 1 \\
& Medical emergency technician & 4 \\
\hline Literacy level & Official personnel of 115 center & 3 \\
& Forensic medicine & 1 \\
& Hospital emergency ward nurse & 4 \\
Work experience & BSc & 5 \\
& MSc & 3 \\
& PhD & 17 \\
& Less than 5 years & 2 \\
\hline
\end{tabular}


USA) version, 20.0 was used to analyze the data.

\section{Results}

The study was conducted in 3 Delphi rounds. The demographics of the participants of the final Delphi round are displayed in Table 1. After exploring 14 papers using the systematic review method [22] and another study carried out with conventional content analysis, the items were integrated, examined, and analyzed by the researchers (the first researcher, and $\mathrm{PhD}$ supervisors and advisors) and the repetitious items were omitted. The items approved by the researchers were submitted to round 1 experts as open-ended questions and they were asked to express their opinions on the mentioned factors. After completing the first Delphi round, 77 related factors were approved. The first round was performed during November and December, 2018. In the second round, 77 factors distilled in the first round were designed in the format of a 5-point Likert scale with open-ended questions and the experts were asked to select one of the choices to eventually arrive at the possible disparities regarding each component and item. After analyzing the results of the second round, 43 components were extracted. The second round was completed during January and February, 2019. The results of the second round are represented in Table 2.

The questionnaire developed on the basis of 43 components extracted from the second Delphi round was distributed among the experts and specialists in the third round and 10 components were selected by experts as superior components. The third round was performed during March to April, 2019. The results of the third round are given in Table 3.

Table 2. Key components affecting prehospital emergency related to preventable road traffic Injuries deaths in the first Delphi round
1. Scene assessment for safety
2. Investigation of accident mechanism
3. Performing triage in the scene
4.Exploration of general condition of the victim

\section{Assessment and maintaining of the airway \\ 6. Examination of possible spinal cord damage \\ 7. Investigation of possible cervical damage}

8. Assessment and maintaining of victim's respiration

9. Assessment and maintaining of victim's blood circulation

10. Assessment of victim's neurological status

11. Performing secondary assessment of the victim during transport

12. Accurate receiving of victim's medical history by the operator (triage nurse on the phone) on the basis of algorithm

13. Conveying of information by the operator (triage nurse operator) to the intended organizations (police, fire-fighting organization, the Red Crescent)

14. Selection of the number of codes dispatched by the unit and ambulance management on the basis of accident severity

15. Selection of type of dispatching code (air ambulance, ambulance, motorlance, bus ambulance) by the unit and ambulance management on the basis of accident severity

16. Suitable responding in the case of rapport with the physician $10-50$

17. Integrated commandership in the accident scene

18. Coordination among rescue organizations, police, the Red Crescent, fire-fighting station, and healthcare

19. Arrival of police in the scene before EMS arrival

20. Coordination with the target hospital for patient transport

21. Selection of the nearest and most suitable hospital for patient transport
22. Protocol of delivery of road traffic victim to hospital

23. Delivery of victim to hospital on the basis of protocol

24. Traumatized victim care guideline by EMS personnel

25. Guideline for communication between police and the Red Crescent

26. The required guideline for using drugs by EMS staff

27. A standard time interval for responding on the phone by triage

28. The time spent from the first phone call to the arrival of EMS technician at the scene and reasons for not observing it

29. The time spent from to the arrival of EMS technician at the scene to the time of moving toward the hospital and the reasons for not observing it

30. The time spent from the time of ambulance movement toward the hospital to the time of its arrival at hospital triage and the reasons for not observing it

31. The time spent from the time of ambulance movement toward the EMS station and the reasons for not observing it

32. Passing of specialized training of scene management by EMS technicians

33. Passing of specialized training of scene management by EMS on-call physicians

\section{Passing of re-education courses by EMS technicians}

35. Passing of re-education courses by EMS on-call physicians

36. Performing list of duties accurately by EMS technicians

37. Completeness of interventions taken by EMS on-call physicians

38. Provision of the required training to the caller by the operator with regard to victim management

39. Equipment of the ambulance on the basis of type (A-B-C) according to victim's needs and condition

40. Completeness of the recommended treatment measures by the on-call physician

41. Sufficient number of personnel on the basis of accident severity 42. Availability of medicinal items in the ambulance on the basis of guidelines 
Table 3. Ten key components affecting prehospital emergency related to preventable road traffic injuries deaths in the third Delphi round

\begin{tabular}{ll}
\hline $\begin{array}{l}\text { 1. Correct history taking of the Injured person } \\
\text { 2. Investigation of possible cervical trauma }\end{array}$ & $\begin{array}{l}\text { 6. Coordination among rescue organizations, police, the Red } \\
\text { Crescent, fire-fighting stations, and healthcare centers }\end{array}$ \\
$\begin{array}{l}\text { 3. The time spent from the first phone call to arrival of } \\
\text { technician at the scene }\end{array}$ & $\begin{array}{l}\text { 8. Arrival of police to the scene before arrival of EMS personnel } \\
\text { 4. The time spent form arrival at the scene to the time of }\end{array}$ \\
$\begin{array}{ll}\text { moving towards hospital } & \begin{array}{l}\text { 9. Equipping the ambulance on the basis of type (A-B-C) with the } \\
\text { required equipment according to the victim's condition }\end{array} \\
\text { 5. Passing of re-education courses by EMS technicians } & \text { 10. Coordination with the target hospital for patient transport }\end{array}$
\end{tabular}

\section{Discussion}

In this study, factors influencing preventable fatal road traffic injuries in the prehospital phase were extracted using three Delphi rounds. Some studies have been conducted in general and some of them are partly due to causes that disrupt pre-hospital emergency services and lead to death. The study aimed to investigate the pre-hospital emergencies of traffic accidents in developing and developed countries, increasing the speed of service and reducing the response time, equipping ambulances and facilities, continuing education of staff employed in ambulances, using manpower with a level High professionalism and job satisfaction are among the factors that can be used to reduce the number of deaths and disabilities caused by RTIs [25]. In a study aimed at the role of pre-hospital emergencies in the provision of medical services, Attention to three trained human resources, equipment and response time are considered as the main infrastructure for the performance of the pre-hospital emergency, but for its impact on preventable mortality, other dimensions should be analyzed in detail [26]. Also, In other categories; factors as effective in reducing mortality rate in the prehospital phase are: manpower, education, communication, transport, equipment and facilities, ICUs, patient contribution and compliance, general safety agencies, patient transport, recording of patient information, public education, supervision and assessment, accessibility of care, crisis and disasters program, and interdisciplinary and interward cooperation [27].

According to studies, various factors as factors associated with pre-hospital emergencies in preventable mortality of traffic accidents exist so that in the present study, while identifying all the factors, due to the difficulty in providing all the factors, the factors extracted from the viewpoint of the priority specialists in order to pay more attention to pre-hospital emergency operations.

On the basis of the items extracted from Delphi rounds, the first item pertained to correct history taking of the injured person. In the scientific literature, the history taking of the injured person has also been emphasized to collect the necessary and complete information [28]. The history taking of the injured in prehospital emergency due to the lack of communication constraints, limited access to injured medical history, and lack of time to gain this history are considered as the source of the risk and error of treatment [29]. Moreover, the other important information for better management of this could be capturing local information for hot spot and spatial analysis, that other studies also indicated on this important point $[30,31]$.

In assessing traumatized victims in the prehospital phase on the basis of PHTLS guideline (Prehospital Trauma Life Support), history taking, primary assessment, primary diagnosis and prioritization, decision-making for patient dispatching or not dispatching or lack of dispatching code and consultation are among the measures that should be taken [32] Correct history taking as the prime factor selected from among the influential factors is of utmost significance in the quality of EMS care. History taking may be optimized through identifying the radical roots of error. Medical history taking of the patient in prehospital emergency care is rendered as the source of therapeutic error and risk due to limited communication, low access to the victim's medical history, and lack of sufficient time for emergency history taking. Many therapists face some problems in their medical investigations on how to communicate with patients and take their medical history. As a result, there are serious deficiencies in the medical history taken [33]. In a study aimed at ability of the emergency medical service Personnel to take patients' medical history, said $58 \%$ were weak and $39 \%$ reported moderate levels, due to the lack of sufficient knowledge, adequate time and inadequacy of the environment, including the causes of failure Getting the correct history taking in the pre-hospital phase was made [34]. About taking medical history in the pre-hospital phase, the clinical technician should know what information should be collected, how to interpret and how to evaluate, and sometimes the role of the process due to lack of training of personnel [35]. Moreover, in the study with aim to assessment of pediatric educational needs among emergency medical services providers, demonstrated that one of the fundamental needs of care-givers in emergency medical services was provision of education on appropriate history taking of patients that presented to this centers since many rescuers showed weaknesses in this regard [36]. In general, 
there are various causes for the capture history, including the lack of adequate knowledge, the lack of ability to structure biographies, lack of attention, poor communication with the patient, lack of motivation, lack of examination communication and sufficient time and inappropriate environment. Considering that the most important causes of system errors are human factors; providing training, planning, developing and upgrading the status of the staff can enhance the motivation of the work, improve the history and provide other clinical services.

Investigation of cervical damage is one of the superior components. Application of cervical collar is one of the important therapeutic interventions in innovative prehospital care of trauma that is prioritized in PTLS guideline of American College of Surgeons and the national guideline of EMS technicians as a procedure with high priority. This indicates the necessity of greater attention of prehospital emergency authorities to education of prehospital care personnel regarding neurological examination of traumatized victims, especially neck and head trauma and multiple traumata in the scene and immobilization of cervical spines using cervical collar to prevent development or aggravation of spinal traumata [37]. Additionally, in study aimed to the nature of therapeutic interventions performed by prehospital care personnel, showed that despite high percentage of multi-trauma and neck and head traumata, only a few victims received cervical collar and backboard and this demands planning and holding educational programs on trauma management for personnel [38]. The results of the prospective study about epidemiology of traumatic cervical spine fractures suggested that cervical collar was used for immobilization in $\% 68$ of traumatized patients transported to healthcare centers by prehospital care staff whereas in $\% 5$ of them no therapeutic intervention was performed [39]. Considering the importance of cervical injuries in traumatic injuries, the proper and timely use of cervical spine in the traffic accident scene should be priorities that should be taken into account as otherwise it can lead to death due to airway obstruction and asphyxiation.

Shortage of communication and coordination is another intervening challenge in preventable deaths, the significant effect of which was approved by the results of the present study. The findings of other studies are also consistent with our results. The results of the study with aimed to identifying barriers for out of hospital emergency care show that the lack of coordination and communication within and outside of the organization was one of the most important barriers to pre-hospital emergency and effective on preventable death [40]. Besides, the study aimed to Management of traumatic injury victims of RTIs, enumerated the following as reasons for prehospital mortality: intervention of unprofessional lay rescuers, lack of coordination and shared attempts, insufficient prehospital services, and deficient infrastructures According to the study aimed to recommendations for pre-hospital emergency systems, in order to agree on a better coordination between the organizations involved in the scene, it is advisable to establish a committee of representatives of each organ to ensure active participation and division of duty [41, 42].

The second and third selected factors pertained to time management. The importance of time management is so highlighted in emergency care that sometimes even seconds are vitally accounted [43]. Considering time intervals and their management can serve as useful indices for assessing EMS performance to plan resources and evaluate patient care quality. The time interval between a crash and onset of care-giving in a healthcare center is an important predictor of victim survival [44].The results of other studies are consistent with our findings on the role of time management. In the study Effectiveness of a program in pre-hospital emergency in trauma, indices of mean time of emergency staff's arrival at the scene, mean time of arrival from the scene to the hospital, and mean time of announcement of mission to arrival at the hospital were used to assess their performance [45]. The study aimed to Comparison of pre-hospital emergencies, the time between mission announcement to arrival at hospital was rendered as an important index [46]. The most important time index in a pre-hospital emergency is the time interval from the moment of call to the arrival of pre-hospital emergency clinicians on the scene [47]. As a standard, the response time in emergency missions is eight minutes. Given that the primary hours and minutes of responding to emergency cases are golden times, decreasing response time will be associated with increased survival of victims and diminished mortality rate. One of the most important reasons of increased response time in emergency missions is the long distance between emergency stations that exceeds the global standards so that an increase in the number of EMS stations would result in decreased response time. The second reason affecting response time is traffic jam and crowded streets [48]. The third influential cause of unusually long response time is the long distance. Also, in survey of Impact of Long-Term Emergency on Mortality in London, the survival rate is $\% 94.2$ for a distance of $0-10 \mathrm{~km}, \% 92.3$ for $11-20 \mathrm{~km}$, and $\% 91.2$ for more than $21 \mathrm{~km}$. As distance increased, the survival rate decreased [49]. According to the study Studying the Time of Response and Results of Delay in Emergency Medical Studying the Time of Response and Results of Delay in Emergency Medical System's missions, the following factors decreased the response time: technicians' familiarity with the shortcut routes, high frequency waves and trucking (automatic radio system) for finding the most suitable route in emergency cases, continued education through mass media to encourage cooperation with emergency services and ambulances for opening 
the route, devoting special routes for ambulances in heavy traffic routes, and the use of substitutes like motorlance in old or crowded streets [48]. In the study aimed to The role of GPS during emergency pre-hospital emergency response reports that the use of GPS in American prehospital emergency has led to rapid localization and reduced response time in emergency cases [50]. Regarding the mentioned cases it can be concluded that time indices in the assessment of health services in pre-hospital emergency system are important and the time issue is mentioned as one of the most important issues related to pre-hospital emergency services and the identification of the causes of this prolongation The time and performance of the pre-hospital emergency room staff is very effective at the time of the response and reaching the patient's bedside and the time of the patient's service in the incident.

The fourth component selected by experts and specialists was the role of education of technicians. Education and proper performance are other approved items. Skillfulness in management and leadership in emergency cases are among the qualifications of prehospital rescuers. Proper education enables rescuers to overcome lack of program and unsuitable performance in unpredictable conditions of communicating with victims, stressful atmosphere, lack of control on the number and type of care, and a limited framework of time for assessing the efficacy of therapeutic interventions [51]. The prehospital immediate care course (PHIC), prehospital Trauma Life Support (PHTLS), and basic trauma life support (BTLS) are specifically taught as necessary courses for prehospital care-givers in different countries. In the study aimed to Factors Affecting CPR in PreHospital Emergency was expressed that the use of electric shock, prompt attendance at the victim's bedside (clinic), and the number of resuscitators are among the most important causes of successful CPR in EMS centers. So, the number of successful CPRs in the prehospital phase can be increased by taking these factors into account [52]. In exploring performance of EMS staff in prehospital triage reported that the moderate performance of EMS staff in prehospital triage is due to general lack of guidelines in the national EMS system. They suggested that re-education courses on triage be held for the staff to promote the quality of care given by them [53]. Pre-hospital emergency personnel must acquire knowledge, attitude and skill in all necessary functions, and continuing training courses are required at recruitment and continuing education, and if they do not hold these courses or are not appropriate to their needs, problems with There will be no compensation, the most important of them being injured due to personnel defects and inadequate performance.

Another influential component was suitable coordination and communication that may increase the quality of prehospital care $[45,54,55]$. Lack of coordination in the healthcare system has led to lack of allocation of sufficient budget and resources predisposing to insufficient care-giving [40]. The rescuers should communicate with other parties like fire-fighters and police involved in the scene once they arrive the scene [56]. The scene commander is the main coordinator to manage the scene during the operations until they restore the scene to the original situation. In most studies, police has been introduced as the coordinating organ in managing the accident scene $[57,58]$. Depending on the type and severity of the accident scene, police can play a significant role in managing the scene. The presence of police in the scene before other organs arrive, is effective in reducing pile-ups and crowding leading to decreased mortality. The required equipment and facilities are the important elements for fulfilling the goals in any organization. The results of the study carried out in all EMS stations in Yazd, on assessing performance of prehospital emergency staff indicated that only $\% 14.3$ of the stations enjoyed sufficient manpower. Additionally, none of the ambulances in the stations had all of the required equipment and supplies. The most severe shortage pertained to managerialtherapeutic-vital equipment so that only $\% 17.4$ of ambulances enjoyed such equipment. The ventilationrespiration equipment had the best status so that $\% 97.9$ of ambulances had this equipment. Further, the results of the study demonstrated that $\% 85.7$ of emergency stations in Yazd suffered from EMS staff shortage [59]. In the study that conducted on the most acute problems faced by EMS in Lithuania, reported that old ambulances and lack of integrated standards for medical education and treatment were influential components leading to weak performance of medical services in that country [46]. Shortage of ambulance equipment reduces the efficacy of prehospital medical services. Therefore, attempts to remove deficiencies and achieve the standard level are mandatory. In the study that survey the clinical equipment of 115 emergency stations affiliated to Torbat Heidarieh University of Medical Sciences and believed that to achieve standards, it is mandatory to pay due attention to resolving deficiencies in GPS system, electro shock device, and list of triage kits [60].

The last influential component in prehospital emergency related to preventable fatal RTIs is the prompt coordination with hospital for victim transport. In a study that examined prehospital medical interventions delivered to traumatic patients, almost all victims were transported to the admitting hospital without any beforehand coordination. Regarding that previous coordination with the admitting hospital will increase the preparation of emergency care team to provide proper services to the victim, the issue of coordination demands serious attention to improve communication in the prehospital phase between the transport team and healthcare centers [38].

The strength of this study was to extract the 
factors influencing the preventive mortality of the pre-hospital emergency due to traffic accidents based on the group's views of the experts and its limitation was the rapid access to the experts who, by coordinating the dates of the meetings and sending the emails to the questionnaire, Limits decreased.

In conclusion, the influential factors affecting the prehospital emergency care related to preventable fatal road traffic injures deaths and finally, the key components from experts' perspectives were selected. The identification of these components and the reasons for not observing them in some accident scenes will improve the prehospital emergency performance and prevent road traffic accident deaths. A questionnaire is being developed using the results of this study to measure preventable fatal road traffic injuries in the prehospital phase.

\section{Acknowledgement}

The authors are grateful to all the scholars and those who collaborated in this study.

Conflicts of Interest: None declared.

\section{References}

1. Krug EG, Sharma GK, Lozano R. The global burden of injuries. Am J Public Health. 2000;90(4):523-6.

2. Swain AH, Al-Salami M, Hoyle SR, Larsen PD. Patient satisfaction and outcome using emergency care practitioners in New Zealand. Emerg Med Australas. 2012;24(2):175-80.

3. Bigdeli M, Khorasani-Zavareh D, Mohammadi R. Pre-hospital care time intervals among victims of road traffic injuries in Iran. A crosssectional study. BMC Public Health. 2010;10:406.

4. Bahadori M, Ghardashi F, Izadi AR, Ravangard R, Mirhashemi S, Hosseini SM. Pre-hospital emergency in Iran: A systematic review. Trauma monthly. 2016;21(2):e31382.

5. Mehmood A, Rowther AA, Kobusingye O, Hyder AA. Assessment of pre-hospital emergency medical services in low-income settings using a health systems approach. Int J Emerg Med. 2018;11(1):53.

6. Schmidt TA, Nelson M, Daya M, DeIorio NM, Griffiths D, Rosteck P. Emergency medical service providers' attitudes and experiences regarding enrolling patients in clinical research trials. Prehosp Emerg Care. 2009;13(2):160-8.

7. Khorasani-Zavareh D, Khankeh HR, Mohammadi R, Laflamme L, Bikmoradi A, Haglund BJ. Post-crash management of road traffic injury victims in Iran. Stakeholders' views on current barriers and potential facilitators. BMC Emerg Med. 2009;9:8.

8. Barnett AT, Segree W, Matthews A. The roles and responsibilities of physicians in Pre-Hospital Emergency Medical Services: A Caribbean perspective. West Indian Med J. 2006;55(1):52-5.

9. McQuillan KA, Makic MBF, Whalen E. Trauma Nursing E-Book: From Resuscitation Through Rehabilitation: Elsevier Health Sciences; 2008.
10. Lockey DJ. Prehospital trauma management. Resuscitation. 2001;48(1):5-15.

11. LeBlanc VR, MacDonald RD, McArthur B, King K, Lepine T. Paramedic performance in calculating drug dosages following stressful scenarios in a human patient simulator. Prehosp Emerg Care. 2005;9(4):439-44.

12. Bucknall TK. Critical care nurses' decision-making activities in the natural clinical setting. $J$ Clin Nurs. 2000;9(1):25-35.

13. Ganveer GB, Tiwari RR. Injury pattern among non-fatal road traffic accident cases: a cross-sectional study in Central India. Indian J Med Sci. 2005;59(1):9-12.

14. Chandran A, Hyder AA, Peek-Asa C. The global burden of unintentional injuries and an agenda for progress. Epidemiol Rev. 2010;32:110-20.

15. Ansari-Moghaddam A, Martiniuk AL, Mohammadi M, Rad M, Sargazi F, Sheykhzadeh K, et al. The pattern of injury and poisoning in South East Iran. BMC Int Health Hum Rights. 2012;12:17.

16. Lankarani KB, Sarikhani Y, Heydari ST, Joulaie H, Maharlouei N, Peimani $\mathrm{P}$, et al. Traffic accidents in Iran, a decade of progress but still challenges ahead. Med J Islam Repub Iran. 2014;28:96.

17. Hogan H. The problem with preventable deaths. BMJ Qual Saf. 2016;25(5):320-3.

18. Khorasani-Zavareh D, Haglund BJ, Mohammadi R, Naghavi M, Laflamme L. Traffic injury deaths in West Azarbaijan province of Iran: a cross-sectional interview-based study on victims' characteristics and pre-hospital care. Int J Inj Contr Saf Promot. 2009;16(3):119-26.

19. Loo R. The Delphi method: a powerful tool for strategic management. Policing: An International Journal of Police Strategies \& Management.
2002;25(4):762-9.

20. Skinner R, Nelson RR, Chin WW, Land L. The Delphi Method Research Strategy in Studies of Information Systems. Cais. 2015;37:2.

21. Dalkey N, Helmer O. An experimental application of the Delphi method to the use of experts. Management science. 1963;9(3):458-67.

22. Eftekhari A, Tafti AD, KhorasaniZavareh D, Nasiriani K, Hajimaghsoudi M, Falahzadeh H. Root Causes of Preventable Prehospital Deaths in Road Traffic Injuries: A Systematic Review. Trauma Monthly. 2019;24(4):e88412-e.

23. Eftekhari A, DehghaniTafti A, Nasiriani K, Hajimaghsoudi M, Fallahzadeh H, Khorasani-Zavareh D. Management of Preventable Deaths due to Road Traffic Injuries in Prehospital Phase; a Qualitative Study. Archives of Academic Emergency Medicine. 2019;7(1):32.

24. Vandentorren S, Salmi LR, Brochard P. Recognition of occupational cancers: review of existing methods and perspectives. Bull Cancer. 2005;92(9):799-807.

25. Ebrahimipour H, Vafaee Nazhad R, Vafaee Najar A, Yousefi M, Houshmand E, Hosseini S. PreHospital Emergency Services With Emphasis on Traffic Accidents: A Case Study in Mashhad, Iran. Health in Emergencies and Disasters Quarterly. 2017;2(3):145-154.

26. Knott A. Emergency medical services in rural areas: the supporting role of state EMS agencies. J Rural Health. 2003;19(4):492-6.

27. VanRooyen MJ, Thomas TL, Clem KJ. International emergency medical services: assessment of developing prehospital systems abroad. J Emerg Med. 1999;17(4):691-6.

28. Birks M, Cant R, James A, Chung C, Davis J. The use of physical assessment skills by registered nurses in Australia: issues for nursing education. Collegian. 2013;20(1):27-33. 
29. Orlik K, Campana CM, Beeson MS, Simon EL. Freestanding EDs and the emergency medicine resident: a valuable part of resident education? Am J Emerg Med. 2015;33(8):1096-7.

30. Goel R, Jain P, Tiwari G. Correlates of fatality risk of vulnerable road users in Delhi. Accid Anal Prev. 2018;111:86-93.

31. Kolifarhood G, Khorasani-Zavareh D, Salarilak S, Shoghli A, Khosravi N. Spatial and non-spatial determinants of successful tuberculosis treatment outcomes: An implication of Geographical Information Systems in health policy-making in a developing country. J Epidemiol Glob Health. 2015;5(3):221-30.

32. National Association of Emergency Medical Technicians. PHTLS: Prehospital Trauma Life Support. 8th ed. Canada: Jones \& Bartlett; 2010.

33. Sobhani A, Shojaei H, Vaghari S, Poormirzaei S, Aranfar B, Ramezanian T. Assessment of record summaries and history taking in internal ward. J Qazvin Univ Med Sci Health Serv. 2000;12:52-8.

34. Sadrollahi A, Gharataghani A, Mahmoudi M. The ability of the emergency medical service Personnel to take patients' medical history. Journal of Emergency Practice and Trauma. 2018;4(2):55-61.

35. Keifenheim KE, Teufel M, Ip J, Speiser N, Leehr EJ, Zipfel S, et al. Teaching history taking to medical students: a systematic review. $B M C$ Med Educ. 2015;15:159.

36. Hansen M, Meckler G, Dickinson C, Dickenson K, Jui J, Lambert W, et al. Children's safety initiative: a national assessment of pediatric educational needs among emergency medical services providers. Prehosp Emerg Care. 2015;19(2):287-91.

37. Asadi P, Asadi K, Monsef-Kasmaei V, Zohrevandi B, Kazemnejad-leili E, Kouchakinejad Eramsadati L, et al. Evaluation of frequency of cervical spine injuries in patients with blunt trauma. Journal of Guilan University of Medical Sciences. 2015;23(92):31-6..

38. Dadashzadeh A, Dehghannejhad J, Shams Vahdati S, Soheili A, Sadeghi Bazarghani H. The nature of prehospital medical interventions delivered to traumatic patients in Tabriz. Journal of Urmia Nursing And Midwifery Faculty. 2017;15(3):159-67.

39. Fredø HL, Rizvi SA, Lied B, Rønning P, Helseth E. The epidemiology of traumatic cervical spine fractures: a prospective population study from Norway. Scand J Trauma Resusc Emerg Med. 2012;20:85.

40. Kironji AG, Hodkinson $P$, de Ramirez SS, Anest T, Wallis L, Razzak J, et al. Identifying barriers for out of hospital emergency care in low and low-middle income countries: a systematic review. BMC Health Serv Res. 2018;18(1):291.

41. Kobusingye OC, Hyder AA, Bishai D, Hicks ER, Mock C, Joshipura M. Emergency medical systems in low- and middle-income countries: recommendations for action. Bull World Health Organ. 2005;83(8):626-31.

42. Zavareh K. Management of traumatic injury victims of road accidents in Iran 2008 [Thesis in Persian]. Tabriz University. 2008.

43. Nguyen HL, Saczynski JS, Gore JM, Goldberg RJ. Age and sex differences in duration of prehospital delay in patients with acute myocardial infarction: a systematic review. Circ Cardiovasc Qual Outcomes. 2010;3(1):82-92.

44. West JG, Trunkey DD, Lim RC. Systems of trauma care. A study of two counties. Arch Surg. 1979;114(4):455-60.

45. Jayaraman S, Mabweijano JR, Lipnick MS, Caldwell N, Miyamoto J, Wangoda R, et al. First things first: effectiveness and scalability of a basic prehospital trauma care program for lay first-responders in Kampala, Uganda. PLoS One. 2009;4(9):e6955.

46. Vaitkaitis D. EMS systems in Lithuania. Resuscitation. 2008;76(3):329-32.

47. Raeissi P, Nasiripour A, Lotf $S$, Abrisham A, Akbarzde M. An Investigation of the Relationship between Job Characteristics of Emergency Medical Technicians and Scene Time in Traumatic Injuries of Mashhad. Journal of Police Medicine. 2013;2(1):47-54.

48. Peyravi M, Moradian M, Ettehadi R, Pourmohammadi K. Studying the time of response and results of delay in emergency medical system in Shiraz. Scientific Journal of Rescue \& Relief. 2013;5(2):30-9.

49. Eaton L. Longer ambulance journeys raise mortality in patients with life threatening conditions. BMJ: British Medical Journal. 2007;335(7616):367.

50. Ota FS, Muramatsu RS, Yoshida $\mathrm{BH}$, Yamamoto LG. GPS computer navigators to shorten EMS response and transport times. Am J Emerg Med. 2001;19(3):204-5.

51. Dadgar M, Taraghi F, editors. An attitude on nursing care and triage in emergency ward. Tehran: 3th international congress of cure and health and crisis management in disaster; 2007.

52. Sadrollahi A, M AK, editors. Study of successful cardiopulmonary resuscitation and its related factors in pre-hospital medical emergency centers. Hospital Emergency: Iran; 2016.

53. Dehghani M, Sharifi A, Afshari A, Darabi MJ. Investigating the performance of emergency medical staff in Hamadan in pre-hospital triage. Hospital Emergency: Iran; 2016. [in Persian].

54. Tannvik TD, Bakke HK, Wisborg T. A systematic literature review on first aid provided by laypeople to trauma victims. Acta Anaesthesiol Scand. 2012;56(10):1222-7.

55. Khorasani-Zavareh $\mathrm{D}$, Khankeh HR, Mohammadi R, Laflamme L, Bikmoradi A, Haglund BJ. Post-crash management of road traffic injury victims in Iran. Stakeholders' views on current barriers and potential facilitators. BMC Emerg Med. 2009;9:8

56. Coats TJ, Davies G. Prehospital care for road traffic casualties. BMJ. 2002;324(7346):1135-8.

57. Esmaeili A AH,Zahiri M. Investigating the role of road policing in the field of road accidents management: Ardabil province. Quarterly Journal of Traffic Management Studies. 2011;5(17):1-23. [in Persian].

58. Amiri M SH, Khankeh $H$, Momeni E, Eini E. Factors Affecting Crash Scenario Management: A Study of Theory of Land in the Islamic Republic of Iran. Quarterly research studies. 2015;3(11):11-30. [in Persian].

59. B Bahrami MA, Maleki A, Ezzatabadi MR, Askari R, Tehrani GA. Prehospital emergency medical services in developing countries: a case study about EMS response time in Yazd, Iran. Iran Red Crescent Med J. 2011;13(10):735.

60. Abbaspour S, Sabbagi M, Tatari M. The Assessment of Clinical Equipment of Emergency Medical Services in Torbat Heydariyeh University of Medical Sciences in 2016. Iranian Journal of Emergency Care. 2017;1(2):1-8.

\section{Open Access License}

All articles published by Bulletin of Emergency And Trauma are fully open access: immediately freely available to read, download and share. Bulletin of Emergency And Trauma articles are published under a Creative Commons license (CC-BY-NC). 